\title{
Study of the curative role of "Draas" in evacuating dunes threatening roads in the Lower Algerian Sahara: physical model on a smaller scale
}

\begin{abstract}
A. K. SEBAA ${ }^{1}$, M. BELHAMRA ${ }^{2}$
Sand drifting on road networks in the region of the Lower Algerian Sahara is one of the main problems for the sector. Machines are repeatedly deployed to overcome this phenomenon. The long experience acquired while dealing with the removal of sand from roads pushed us to focus on obstacles called "Draas". The purpose of this study is to perform an optimization of these special protective structures called "Draas", using a reduced physical model. Model tests were performed in flow channel. The principle of modeling the wind transport using a reduced model is to simulate the wind using a liquid stream while respecting the laws of hydraulic and sedimentological similarity. The results obtained are extrapolated to make a normal size prototype.
\end{abstract}

Keywords: Road networks, sand drifting, anti-sand walls, reduced model, Lower Algerian Sahara.

\footnotetext{
${ }^{1}$ Abou Bekr Belkaid University, Faculty of S.N.V /S.T.U, Department of Ecology and Environment, Rocade 2 P.O. Box 119, Tlemcen 13000, Algeria, and Scientific and Technical Research Center for Arid Areas (CRSTRA), Omar ElBernaoui, P.O. Box 1682, Biskra 07000, Algeria, E-mail:sebaat@yahoo.fr

${ }^{2}$ Laboratory for Ecosystem Diversity and Dynamics of Agricultural Systems in Arid Regions - University Mohamed Khider, Biskra, Algeria, E-mail: segmadz@yahoo.fr
} 


\section{INTRODUCTION}

The Lower Algerian Sahara shows harsh natural constraints. The most visible ones are those related to wind dynamics which affect many regions. Among the most important of these regions are Oued Souf and the region of Ouargla (Taibet, Hassi Messaoud) (fig. 1).

Due to these very delicate geographical situations (located at the northern borders of the "Grand Erg Oriental" or Great Eastern Erg), the wind sets in motion significant amounts of sand which come to clutter many socio - economic infrastructures, and particularly roads which constitute a vital means

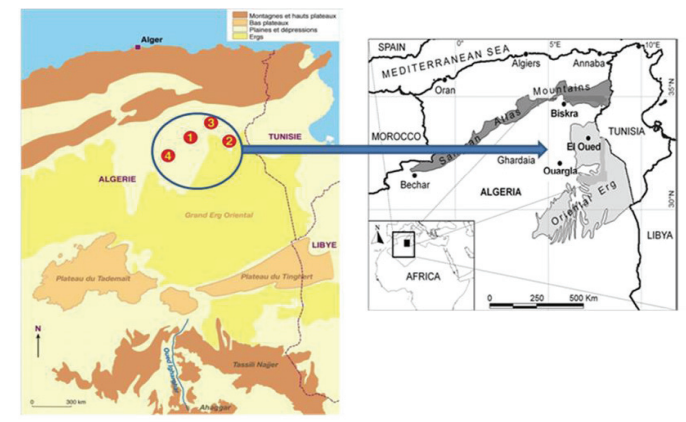

Figure 1. Overall map of Lower Algerian Sahara. 1 : Oued Righ. 2 : Oued Souf. 3 : Biskra. 4 : Oued M'ya (From Ballais, 2010).

of communication for these regions. A very large budget has been granted to open up the southern region of Algeria through the construction of roads. However, these infrastructures are still threatened by the phenomenon of drifting sands caused by the combination of strong winds, arid soils, lack of vegetation, and aggravated by the scarcity of rainfall, mainly on road sections RN3, RN16 and RN53A (Moudjahed, 2007). These communication routes require regular removal of sand and maintenance, sometimes urgent. They require significant material and human resources as well (fig. 2). It is clearly understood that removing sands from roads and keeping them in good condition necessitate very large financial resources (fig. 3). Moreover, this phenomenon is not only 
bad for traffic, but it is also the cause of many serious traffic accidents, especially during great sand movement (Sebaa et al., 2009).

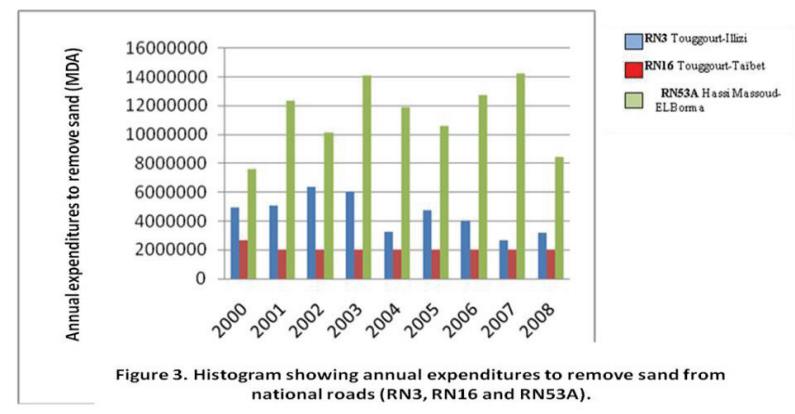

Considering this phenomenon, great efforts have been made and significant works (technique of fences, mulching and sand removal) have been completed by industry members in order to effectively fight this phenomenon, both at the curative as well as the preventative levels. But all these techniques are quickly overwhelmed by the arrival of mobile dunes. A possible solution to this phenomenon is to construct small barriers made of heavy and compact materials, which facilitate the removal of sand from the site to protect, and prevent its accumulation on the roadway. According to (Voisin, 2004), these barriers, traditionally called "Draas", must be oriented according to the terrain contours and also to the direction of action of prevailing winds. Longitudinal and transverse corridors must be arranged between These Draas in order to make the prevailing winds work against their natural impulses; sand is therefore drifted away from the roads and will certainly not accumulate on the road. Hence, wind becomes a more efficient transport and cleaning agent. This type of sand clearing is based on the aerodynamic effect of changes in wind speed or direction, on its acceleration or the turbulences which allow the wind to resume accumulations by increasing its load capacity (FAO, 1988). The "Draa" is made of an oblong heap of sand and stabilized by coarse material and / or stones. 
For this reason, it is desirable to increase the effectiveness of these protective barriers, "Draas", to better understand the mechanism of their functioning and to optimize their use through a technical and scientific study of a small-scale physical model whose results will be extrapolated for the realization of full-scale prototypes.

The reduced-scale model tests have been carried out at the Laboratory of Maritime Studies, in a flow channel whose geometric dimensions are determined and studied in order to obtain a series of appropriate speeds. The principle of modeling wind transport in a reduced model is to simulate wind with a liquid stream while respecting the hydraulic and sedimentological Similarity laws.

\section{MATERIALS AND METHODS}

\subsection{Experimental setup (flow channel)}

Several attempts have been made to design an experimental setup to simulate wind at the Laboratory of Maritime Studies. Domestic fans were first supposed to be used, but were then dismissed because the air current obtained was not powerful enough. Then, after prospection, a blower was designed and manufactured (F. Naaim - Bouvet et al. 1996). The geometric dimensions and air flow were determined in order to obtain the maximum speed range that corresponds to that found at the study site.

The experimental setup (fig.4) used in the tests consists substantially of:

- A prismatic flow channel made of concrete, with a bay window, 8 meters long, 0.52 meters wide and 0.60 meters high. The channel is horizontal, with two distinct parts:

- An upstream portion, where solid particles are injected through a damping gate of the flow to avoid the hydraulic jump;

- A downstream part which consists of a bay window to allow visualizing the flow, the transport of particles and the areas of sand deposit. The obstacles and the road are of different sizes and are positioned at various distances.

- Water is supplied to the model via a reservoir with a constant load, which is fed by two pumps 
(1201/s and $501 / \mathrm{s})$. The flow is regulated by means of two valves. The model is equipped with a triangular weir that allows, using a limnimeter, to measure the water level and calculate the fluid flow.

- Sediment trapping occurs downstream of the channel in the exhaust system.

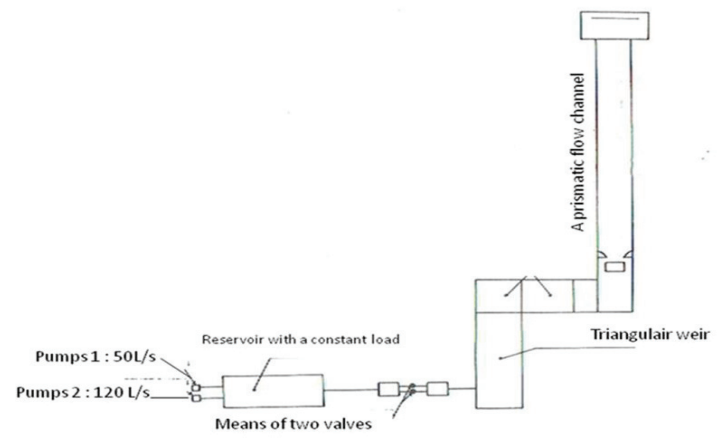

Figure 4. Top view of the experimental setup in flow channel $(\mathrm{ECH}: 1 / 50)$

\subsection{Performing the tests}

2.2.1. Preliminary tests and model calibration

Preliminary tests are required for the development of different parameters, namely:

- The speed range inside the test chamber must be uniform. So, several velocity profiles, at different sections, are measured for various airflows.

- The materials used allow determining the motion of particles and also measuring the corresponding critical speed. This is done with various materials, having different particle sizes, but with the same density, or vice versa. It is worth noting that these materials are chosen so they do not give the effect of a dust wind. 
- Study of the aerodynamic profiles (from the geometric dimension perspective):

- These tests are carried out without injecting the solid particles. This task aims to measure the speeds and determine the variation of the speed profiles around the obstacle, in order to find the areas of return currents.

- The shape of the aerodynamic profile is tested while taking into account the geometric dimensions which are determined using the similarity scale (distortion coefficient).

- Finding the optimal position of the material relative to the model, and the position of the model with respect to the road axis.

The objective of these tests is to check the dimensions of the test chamber.

2.2.2. Calibration of the model (hydraulic adjustment)

The hydraulic adjustment allows measuring:

- the flow rate for different openings of the valve

- the speeds of each flow.

2.2.3. Construction of the transversal profile of both the road and the obstacleThe tests are executed as follows:

- Placing the mobile bottom (sand) with a density equal to 2.65 and a layer of $05 \mathrm{~cm}$.

- Measuring the landscape status before generating the liquid stream.

- Generating the liquid stream with a series of speeds that correspond to those of natural wind.

- Injecting a solid flow upstream of the channel.

After each test, a sample of the equilibrium profile is assessed. This process allows evaluating the effectiveness of each arrangement of the obstacles relative to the road axis.

\subsection{Program of tests using a reduced model}

The road parameters and those of the Draa, tested in a reduced physical model, are shown in Table 1. In life-size, three (03) test series were tested with their corresponding variants. One should recall that the section tested using a reduced model is about $30 \mathrm{~m}$ long in life-size. 


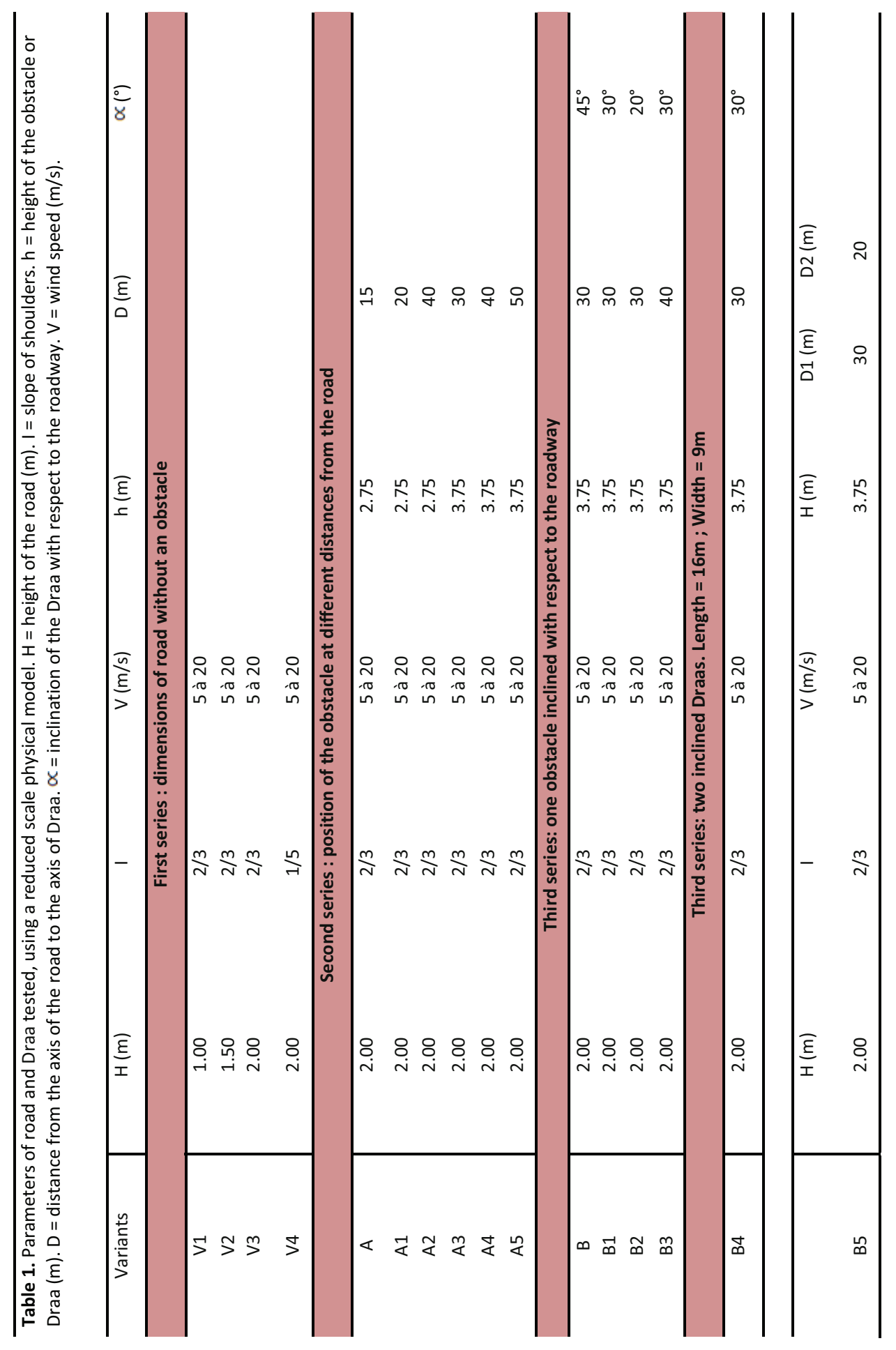




\subsubsection{First series}

This aims to test the typical profile of the road which is considered as an obstacle. It also enables to determine the equilibrium profile of the road without protection as a function of:

- the range of speeds of the generated current,

- the height of the road,

- the slope of shoulders.

For this reason, the height of the road was tested, for three different heights, i.e. $1 \mathrm{~m}, 1.5 \mathrm{~m}$ and $2 \mathrm{~m}$; the slope of the road was $2 / 3$ for all variants. A test was done with $\mathrm{H}=2 \mathrm{~m}(\mathrm{H}=$ height of the road $)$ with a slope of $1 / 5$, in order to show the importance and the role that the slope of shoulders plays in the layout of the Saharan roads, and finally to determine the optimal distance for placing the Draas with respect to the axis of the roadway. One must know that the local authorities have built Draas at a distance that varies between 10 and $20 \mathrm{~m}$.

Three speeds were chosen, i.e. one minimum, one average and one maximum.

\subsubsection{Second series}

To study this series, one must first test the role of the Draa as an obstacle, by determining its geometric characteristics as a function of its retention capacity as well as the position of the deposit of sand relative to the axis of the roadway. It should be noted that the Draa was placed successively at $15 \mathrm{~m}, 20 \mathrm{~m}$ and $40 \mathrm{~m}$ from to the axis of the road. As for the height of the Draa, it was tested at $2.75 \mathrm{~m}$. In variants $\mathrm{A} 3, \mathrm{~A} 4$ and $\mathrm{A} 5$, the height of the Draa $(\mathrm{h}=3.75 \mathrm{~m})$ as well as the distance separating the axis of the road from the Draa were changed. The distance took the values $30 \mathrm{~m}, 40 \mathrm{~m}$ and $50 \mathrm{~m}$. The Draa had a length of $20 \mathrm{~m}$.

\subsubsection{Third series}

This series of tests was carried out by changing the inclination of the Draa relative to the road (variants B, B1, B2 and B3). These tests were performed for the angle of inclination ( $\propto$ ) equal to 45 ${ }^{\circ}, 30^{\circ}$ and $20^{\circ}$ relative to the road. The Draa was $3.75 \mathrm{~m}$ high; the distance chosen was $30 \mathrm{~m}$. Variant B4 tried to test the efficiency of two Draas placed obliquely. The angle of inclination with respect to the perpendicular of the road was $30^{\circ}$. The distance separating the two Draas was $12 \mathrm{~m}$. The geometrical dimensions of the Draas tested in this variant were $16 \mathrm{~m}$ long and $9 \mathrm{~m}$ wide. In 
variant B5, the Draas were placed parallel to the road; the distance between the axis of the first Draa and that of the road was $30 \mathrm{~m}$, and the distance separating the two Draas was $20 \mathrm{~m}$. Each of the two Draas was $16 \mathrm{~m}$ long and $9 \mathrm{~m}$ wide .

Each variant was treated with different speeds. Each test lasted 30 minutes. This corresponds to a wind storm of $16 \mathrm{~h}$ in real life.

\section{RESULTS}

The results of the tests of series 1 . Variant V1 was tested for the road profile with a height of $1 \mathrm{~m}$ and a slope of $2 / 3$, for the speeds $\mathrm{V} 1=5.09 \mathrm{~m} / \mathrm{s} ; \mathrm{V} 2=8.69 \mathrm{~m} / \mathrm{s}$ and $\mathrm{V} 3=11.57 \mathrm{~m} / \mathrm{s}$. This test allowed to determine the portions that could be covered by sand and to quantify the amounts of sand deposited on either side of the road. This same test also showed erosion over a distance of about $73 \mathrm{~m}$ upstream of the road, with an accumulation of sand of about $2500 \mathrm{~m}^{3}, 1.2 \mathrm{~m}$ high.

As for the side facing the wind, the largest quantity, i.e. $4500 \mathrm{~m}^{3}$, was deposited in the leeward part, over a distance of about $100 \mathrm{~m}$ from the axis of the road. In conclusion, variant V1 shows significant sand drifting for different speeds. The test for variant V2 was done for a road height equal to $1.5 \mathrm{~m}$ and a shoulder slope of $2 / 3$. This variant showed that increasing the elevation of the road does not affect the process of sand deposition. In variant V3, the road was considered to have a height of $2 \mathrm{~m}$ and a slope of $2 / 3$. In this variant, erosion was observed over a distance of $117 \mathrm{~m}$ upstream of the road, with a deposit of $1600 \mathrm{~m}^{3}$ of sand near the road; there was a total removal of sand on the downstream portion of the road. This variant showed, for different speeds, that the road profile plays a key role in the removal of sand compared to the previously tested variants. In variant V4, the shoulder slope of the road was changed. For this purpose, a 2 meters high road with a shoulder slope equal to $1 / 5$ was tested. This variant showed that sand was deposited far away from the roadway, over a distance of $45 \mathrm{~m}$ for the minimum speed $(\mathrm{v}=5.09 \mathrm{~m} / \mathrm{s})$. For the average and maximum speeds, sand deposit was found close to the road, with erosion of the leeward part(fig 5). 


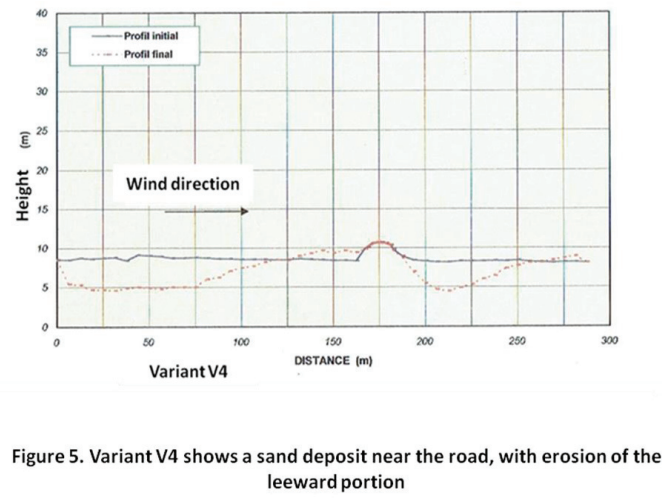

The results of the second series. Variant A aimed at testing the position of the $2.75 \mathrm{~m}$ high Draa, put at a distance of $15 \mathrm{~m}$ from the axis of the road, for the range of speeds between $\mathrm{V} 1=5.09 \mathrm{~m} / \mathrm{s}$ and $\mathrm{V} 2=8.69 \mathrm{~m} / \mathrm{s}$. Erosion was noticed on a distance of about $30 \mathrm{~m}$ in the immediate upstream portion of the road, with a significant accumulation of sand, more than $2.5 \mathrm{~m}$ high, covering both the Draa and the road. However, the leeward side shows severe erosion at the foot of the road. In conclusion, it was noted that putting the Draa at $15 \mathrm{~m}$ from the road accelerates the accumulation of sand. When the obstacle was positioned at a distance of $20 \mathrm{~m}$ (variant A1), sand was not removed from the road. For variant A2, the Draa was placed at $40 \mathrm{~m}$. This variant showed that sand accumulates in large quantities upstream of the Draa. In variant A3, the Draa $(3.75 \mathrm{~m} \mathrm{high})$, and the distance $(30 \mathrm{~m})$ between the Draa and the road were modified. It was observed that sediments were significantly torn off, upstream of the Draa, on a distance of about $100 \mathrm{~m}$. Some of these sediments accumulated on the Draa, forming a deposit more than $2.50 \mathrm{~m}$ high. Sediment pull-out, between the Draa and the road as well as from the leeward part, caused significant erosion. Variant A4 allowed for the accumulation of sand in the upstream part of the Draa, for the considered speed range, with erosion between the road and the Draa and in the leeward part. This profile provided adequate protection (fig 6). In variant A5, the distance separating the axis of the Draa from the road is changed to $d=50$ $\mathrm{m}$. This distance is the maximal distance for the position of the obstacle. Severe erosion, along with 


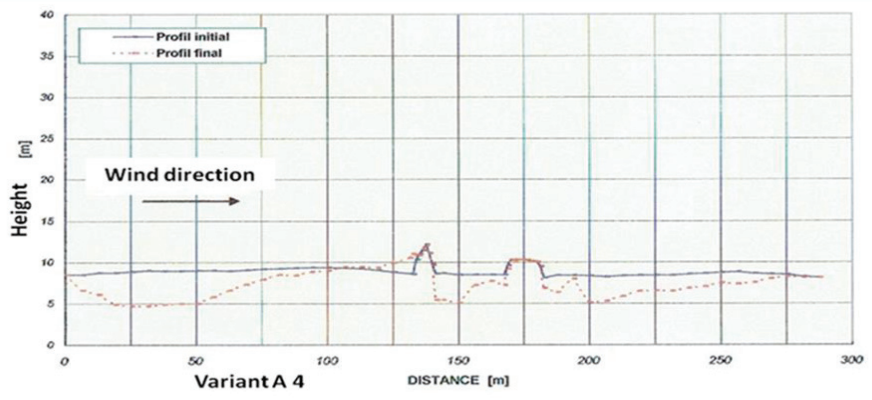

Figure 6. Variant A4 shows erosion followed by a deposit in the upstream portion of the Draa

sand deposition, was observed upstream of the Draa, between the road and the Draa. An important displacement of particles was observed; it extended to the leeward portion. This variant offered a satisfactory protection profile.

Results of the third test series. The obstacle (Draa) in this variant (variant B) was inclined at an angle of $45^{\circ}$ relative to the parallel to the road. The distance between the axis of the road and that of the obstacle was $30 \mathrm{~m}$, and the height of the Draa $3.75 \mathrm{~m}$. This test showed a significant tearing of sediments upstream of the Draa, followed by a deposit of sand. Erosion occurs primarily between the Draa and the road, and in the leeward part. This sand deposition allowed for the trapping of sediments before they reach the road. Tests in variant B1 (Draa inclined at $30^{\circ}$ ) led to the same observations as the previous ones. For a $20^{\circ}$ inclination of the Draa relative to the axis of the road (variant B2), significant erosion was found upstream of the Draa, with an accumulation of sand on the upstream face of the obstacle, which is approximately $1.5 \mathrm{~m}$ high. Severe erosion was noted in the portion between the Draa and the road as well as in the leeward part. Two parameters were modified in variant B3, namely the distance (d) separating the Draa axis from the road axis $(\mathrm{d}=$ $40 \mathrm{~m})$ and the inclination angle $\left(\propto=30^{\circ}\right)$. This variant allowed for a rapid removal of sand from the road. Variant B4 was meant to test the efficacy of setting two Draas obliquely. Sediments were 
significantly torn off, causing severe erosion on the side facing the wind (upstream of the two Draas, between the two Draas, and between the road and the Draa). Downstream of the road (leeward part), erosion took place at the foot of the road, followed by the formation of micro-dunes, far from the axis of the road. The frontal direction for this alternative gave satisfactory results. However, the other directions could not be tested in a flow channel, because this would require a three-dimensional model that would lead to more reliable results. In variant B5, the Draas were placed parallel to the road. Important erosion was observed for the maximum speeds (V2 $=15.24$ $\mathrm{m} / \mathrm{s}$ ), followed by a deposit of sand upstream and downstream of the first Draa. There was intense stripping of particles along the tested profile. This variant allowed for the trapping of sand by the obstacle on the one hand, and also allowed for its removal from the road, on the other (fig 7).

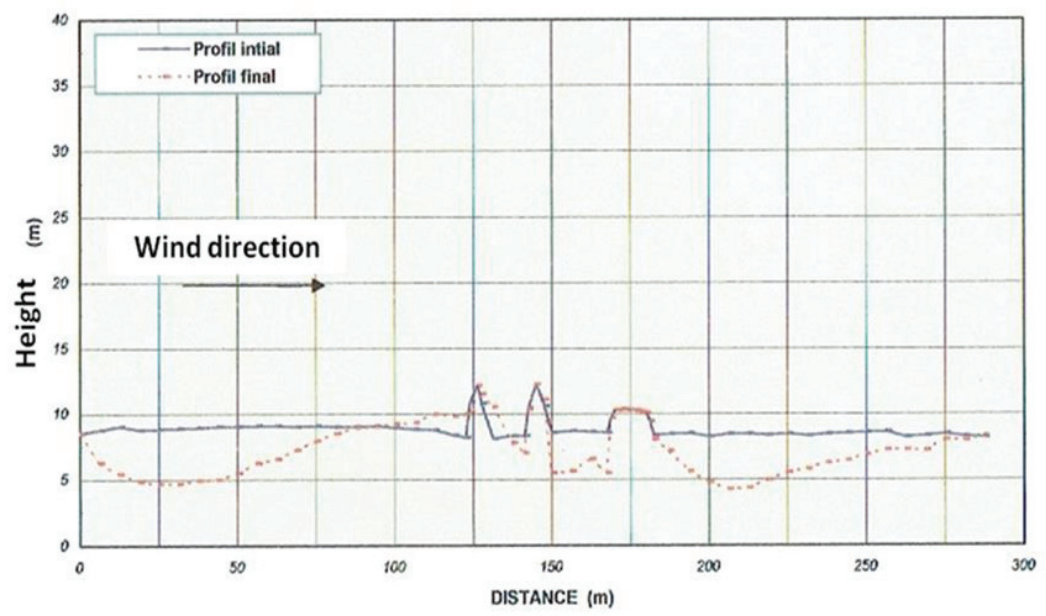

Figure 7. Advantage of positioning two Draas parallel to the road 


\section{DISCUSSION}

The Draas have been tested in the town of El-Oued, since 1965. The prototype of a metallic Draa made of reinforced sheet metal has even been developed in workshops, in the town of Ouargla. It can be dismantled in order to identify the key parameters that govern the onset of the sand drifting phenomenon. Draas are levees of eolian sand that form on the natural slump slope; they are oblong and stabilized by coarse materials and/or stones which lay on the ridge, along the embankment. These artificial barriers are positioned at a distance between 10 and $20 \mathrm{~m}$ from the roadway, each having a specific height, placed in one, two or more rows, and oriented so as to deflect the wind and prevent the accumulation of sand on the road. Specialists in charge of the construction of these Draas are supposed to know how to determine the position, orientation, number and volume of these artificial barriers, whose surface is stabilized with a covering of gypsum rocks. This study aims to optimize the physical reduced model of the protection structure (Draa, a traditional solution to fight desertification in the region of Oued Souf), against sand drifting onto roads. This helps Avoiding any deposit of sand near or on the road.

Variants of the first series showed that the geometric shape of the road plays a key and fundamental role in the phenomenon of sand accumulation on roads. In order to give a view of the most possible aerodynamic cross sectional profile, areas of high embankments and passage cuttings should be kept to a minimum. These tests enabled to conclude that a Saharan road can prevent sand from accumulating if it has a shoulder slope of $1 / 5$ for an embankment profile, instead of 2/3 and 1/10 for a sunken profile. The optimal distance obtained from the tests crosses an area that has a radius of approximately $50 \mathrm{~m}$ from the axis of the road.

The second test series aimed primarily at testing the role of the Draa as an obstacle. According to Mainguet and Remini (2004), when a fluid hits an obstacle, convergences and divergences appear

(fig 8). As wind hits an obstacle, it bypasses it from the top then goes down its backside and resumes its journey. Before and behind the barrier, a mass of compressed air forms, over which air streams glide at high speeds: 


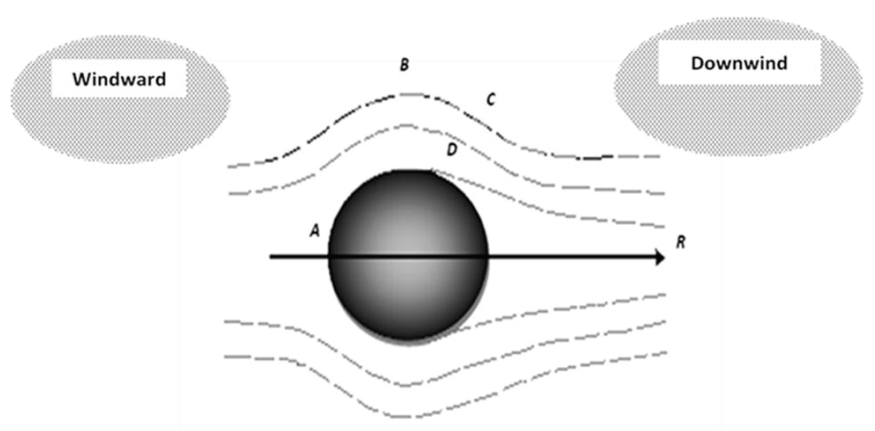

Figure 8. Dynamic behavior of wind circulation in the presence of an obstacle (Mainguet and Remini, 2004)

- At the front, at point A which is called the breakpoint of the upstream portion of the obstacle, the pressure is maximum and the speed is low or equal to zero. In the case of a wind circulation, this

Are a becomes a sand deposit point.

- Applying Bernoulli and Boyle's Law (which says that when fluids are in motion, the product

of pressure and speed is constant), between points A and B, leads to Venturi's phenomenon. This practically means that, in an air stream, when speed increases, pressure decreases. Therefore, converging air streams behave as though they were moving through a constriction, with a speed increase and a pressure decrease. Conversely, when these same air streams are divergent, the pressure increases as the velocity decreases (Mainguet and Dumay, 2006). It may seem paradoxical that, in line with the wind, the slope of the side facing the wind acts as an important factor in the transportation of sand by wind. On the fluid stream $\mathrm{ABC}$, the pressure decreases, the speed increases and the air streams meet there a mass of compressed air which they use as a ramp. These air streams move up the obstacle, on top of which they compress and accelerate. This is an area of erosion and transport, where the eolian corrasion may be active. 
- Beyond point $\mathrm{B}$, the pressure increases again and the speed decreases abruptly; this makes the fluid streams move away from the obstacle. this is known as the detachment area. - Point $\mathrm{D}$ is the detachment point. Beyond it, the velocity on the wall is opposite the flow direction. Thedetachment points on the wall surface give birth to a detachment line. - From point $\mathrm{D}$, the surface layer separates from the wall and forms a vortex trail. This area shows a sand deposit only at the end of the trail.

- In the downstream portion of the trail, the point of reattachment is the starting point of the maximum deposit area. The reattachment area is rich in sandy deposits. After the sandstorms are deflected by the obstacles, they continue on their initial direction.

From the tests performed in a flow channel, for the different variants of the second test series (road dimensions with an obstacle), it is easy to note that sediment accumulation takes place upstream of the Draa for the considered speed range. However, erosion appears between the Draa and the road, as well as in the leeward part.

The inclination of the Draa relative to the axis of the road $\left(45^{\circ}, 30^{\circ}, 20^{\circ}\right)$ caused erosion between the road and the Draa, as well as in the leeward portion. This can be explained by the fact that:

- sand is trapped by the obstacle before reaching the floor

- sand is removed from the road, while the downstream part is empty.

When two Draas are set slantwise, for the range of tested speeds, sediments are violently torn off. This causes significant erosion in the part facing the wind. In the leeward part, there is erosion along with micro-dunes formed away from the axis of the road. In this case, the Draas, placed obliquely to the road, play a dual preventive role.:

1. With respect to winds coming from direction A, they serve as a sand shield. Some deposits of sand may form.

2. With respects to winds coming from direction $\mathrm{B}$, they play the roles of conduits and accelerators at the same time. Winds remove the previous deposits and move them over the road without falling. The optimal orientation obviously depends on the direction of the local winds which have a force greater than a given value. In this case, the Draas channelize and accelerate the winds. In such a 
situation, the wind picks up the sand from the dune which is eroded and pushed away further. Such a test has given very satisfactory results on the route from Touggourt to Djelfa (fig 9).

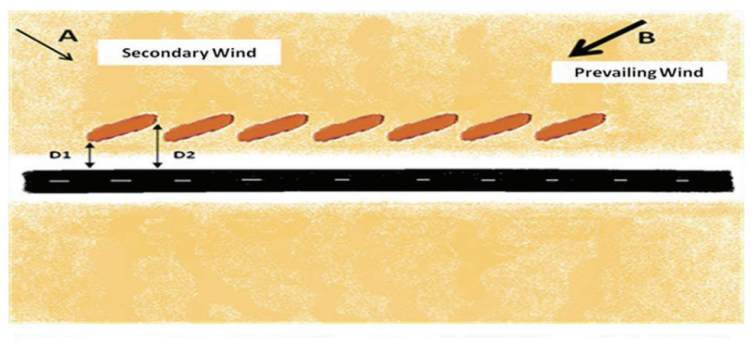

Figure 9. Design and positioning of Draas slantwise

The test carried out with the two Draas placed parallel to the road, at approximately $30 \mathrm{~m}$ from its axis, allowed trapping sand by the barrier (obstacle) on the one hand, and removing it from the passage on the other. Draas act as accumulators, screens and sand removers; however, they can be efficient only if they are frequently and regularly cleaned. If their cleaning is not possible, then these Draas become a danger as they enhance the formation of dunes along the roads. For this reason, this technique of Draas, parallel to the road, was somewhat abandoned. It was taken up again by 1991 in the region of El-Oued, but in a slightly different form, i.e. the Draas were placed slantwise with respect to the road (Remini, 2006). The setup used is essentially based on the void or space existing between the embankment levees (V1) and (V2). These form a discontinuity between the embankments which are opposed to the prevailing wind (zigzag arrangement). V1 varies between 3 and $4 \mathrm{~m}$ and V2 between 14 and $16 \mathrm{~m}$. The Draas are placed at a distance (D) which can vary from 10 to $15 \mathrm{~m}$ from the platform. Their height is around $3 \mathrm{~m}$, and the length (L) varies between 14 and $16 \mathrm{~m}$. When the erosive wind blows, turbulences are created near each Draa, and a swirling vortex, more drying than the normal wind (Mazerand, 1971 In Soltner, 2005), appears at a distance equal to 2 times (denoted " $2 \mathrm{~h}$ ") the height of the obstacle, with a 5 times depth $(5 \mathrm{~h})$. Measurements show that the wind arrives with a speed of $5 \mathrm{~m} / \mathrm{s}$ and leaves with a ground speed of 9 $\mathrm{m} / \mathrm{s}$ (Coudé-Gaussen, 1991). Thus, sand does not settle but transits. Wind erosion occurs at the base 
of each embankment that tends to go down. Moreover, between the three embankments, there is a vortex effect, resulting in an acceleration of the wind speed which causes its kinetic energy to increase. In this case, the dune subjected to such an action gradually shrinks and eventually leaves the Draas on the spot (fig 10).

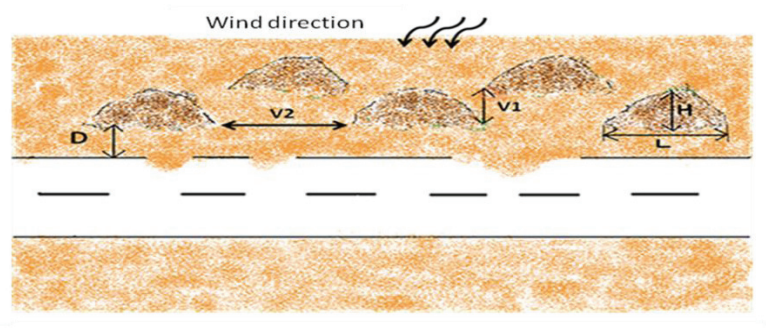

Figure 10. Design and positioning of Draas in Zigzag

These aerodynamic processes, which make the wind act against itself, are the most ingenious of all the processes of sand removal. These techniques use the strength and speed of wind itself to displace the sand. The structures should not impede the flow of sand. This can be a very effective solution, which is based on the same principle as the previous techniques and is already used on the national road RN 16, joining Touggourt to El-Oued Souf. In the case of large dunes (linear dunes, called Sif ), large sharp embankment heaps, of conical shape, can be installed on the ridge of each dune, upstream of the site to be protected, to push sand away (Remini, 2006). The embankments, of conic form, with the help of wind, create around them a zone of turbulence that causes the removal of sand quite rapidly and hence a gradual reduction in the sandy heap. The conical embankment heap decreases as the crest of the dune lowers. The Draas help the wind speed to increase along an inclined plane, in the form of a trapezoid, in the immediate vicinity of the road. This technique is very efficient to completely neutralize a dune by wind. A concrete example of this setup is used on the national road RN 16, from Touggourt to EL-Oued Souf. 


\section{SUMMARY AND CONCLUSION}

Some adverse consequences of wind dynamics are worth mentioning; several oil infrastructures, such as oases and settlements are covered with sand due to the wind dynamics. The small erg which covered the ruins of the Ibadites districts of Sedrata, in the south of Ouargla, is a good example [14]. Roads and hydro-agricultural infrastructures are not spared by this phenomenon. Even the railway joining Touggourt to Biskra suffers from this problem; after a sandstorm, it is usually cut at Touggourt - Djamâa [3]. Therefore, great efforts are often used and considerable work (palisade technique, mulching and dredging ...) is done by the technical teams and farmers in the area under study in order to efficiently fight against this phenomenon, at the curative as well as at the preventive levels. Unfortunately, all these techniques are quickly overwhelmed by the arrival of mobile dunes. Nevertheless, placing protective barriers or "Draas", according to a traditional technique, allowed to slightly reducing the frequency of the mechanical removal of sand from certain parts of the road, and their maintenance as well. This study aims at increasing the efficiency of these protective barriers, "Draas", to better know their operating mechanism and optimize their use through technical and scientific studies using a physical reduced model whose results will be extrapolated to build a full-scale prototype.

At the end of the tests conducted using a reduced model, it was found that: Variants of the first series of tests showed that the geometric shape of the road plays a decisive and fundamental role in the phenomenon of blocking roads with sand. The main results indicated that: - A Saharan road alone,with a shoulder slope of $1 / 5$ instead of $2 / 3$, can remove sand. - The road level must be higher than $1 \mathrm{~m}$.

Regarding the second series, placing the $2.75 \mathrm{~m}$ high Draa at $15 \mathrm{~m}$ and $20 \mathrm{~m}$ from the road accelerates the accumulation of sand on the road. But if a $3.75 \mathrm{~m}$ high Draa is put at 30,40 and 50 $\mathrm{m}$ from the road, then sediment accumulation occurs upstream of the Draa, for the speed range under consideration, and erosion occurs between the Draa and the roadway, and also in the leeward portion.These tests indicated that sand was removed from the roadway. For the third series of tests, the arrangement of two Draas parallel to the road, at approximately $30 \mathrm{~m}$ 
from the roadway, gave satisfactory results. The inclination of the Draa relative to the axis of the roadway caused erosion between the roadway and the Draa, as well as in the leeward portion.

The tests carried out with a reduced model indicated that the appropriate distances for placing the $3.75 \mathrm{~m}$ high Draas, parallel to the road, are 30,40, and $50 \mathrm{~m}$ from the roadway (variants A3, A4, A5). Variant A3 is the one recommended when the barrier is placed parallel to the roadway; variant B5 is the one recommended in the case of two parallel Draas. However, if the Draa is positioned at an angle and is subjected to a frontal wind, B1 variant is preferred. It is obviously clear that to study the efficiency of Draas, positioned at an angle relative to the axis of the road, only a threedimensional study, based on a reduced-scale physical model, can be used to draw reliable and interesting conclusions for this study.

From the results obtained with a reduced model, the field survey section allowed tracking the behavior of these protective barriers (Draas), as well as the effectiveness of the parameters obtained in the laboratory, during several years of observation, follow-up, and long interesting conversations with local people. The results obtained in the field are very encouraging; they proved to be efficient over time. The models of mechanical stabilization of the installed dunes remain intact and confirm once more their efficiency against the aggressive action of winds. The Draa technique came to fill the gaps and find a practical and durable solution for the removal of dunes threatening roads. Compared to other mechanical techniques, these small barriers are more interesting because they are easy to install, they have a long lifetime, and are less costly. The possibility of mechanization of this technique offers great prospects.

The findings as well as the recommended variants in this study allow considering the second phase of the so-called experimental study, i.e. monitoring the on-site testing of Draas in order to assess the amounts of sand displaced or removed, by measuring the eolian erosion flows, using sand traps, and micro-meteorological parameters associated with each erosive event. 


\section{ACKNOWLEDGEMENT}

We would first like to thank my colleagues. For their wonderful collaboration. You supported me greatly and were always willing to help me. We would particularly like to single out my thesis director Ms. Mohamed Belhamra, We want to thank you for excellent cooperation and for all of the opportunities We was given to conduct my research.

\section{REFERENCES}

1. J.L. Ballais, "Des oueds mythiques aux rivières artificielles : l'hydrographie du Bas-Sahara Algérien" , Physio-Géo. Géographie physique et environnement Vol IV. pp. 107-127, 2010.

2. Cahiers FAO," Manuel de fixation des dunes", Cahiers conservation $N^{\circ} 18$, Rome. 68p, 1988.

3. M. Côte, "La ville et le désert, le Bas-Sahara Algérien" Ed Karthala et Iremam, Paris, Aix-enProvence, 306p, 2005.

4. G. Coudé-Gaussen, "Les poussières Sahariennes. Coll. Sciences en Marche", John Libbey, Eurotext, Paris, 485p, 1991.

5. M. Mainguet, B. Rémini, "Le rôle des méga-obstacles dans la formation et le façonnement des ergs : quelques exemples du Sahara", Laboratoire de Recherche en Hydraulique Souterraine et de surface. Journal $\mathrm{N}^{\circ}$ 3. pp. 13-23, 2004.

6. M. Mainguet, F. Dumay, "Combattre l'érosion éolienne: un volet de la lutte contre la désertification", Les dossiers thématiques du CSFD. № 3. Montpellier : Agropolis. 44p, 2006.

7. N. Moudjahed, "Protection des routes contre l'ensablement : cas des RN 3, RN 16 et RN 53A", In CRSTRA, éd. Actes des journées d'études et de sensibilisation sur la quantification du sable en transit éolien et sur la lutte contre l'ensablement. Biskra : CRSTRA. pp. 53-71, 2007.

8. F. Naaim-Bouvet,"La protection du col d'Engeyresque (A75) Modélisation physique en soufflerie et à l'extérieur de la formation de congères", In Annales des Ponts et chaussés $\mathrm{N}^{\circ}$ 73. pp. 27-41, 1995.

9. F. Naaim-Bouvet,M, Naaim, "Modélisation physique en soufflerie et à l'extérieur du transport de la neige par le vent", In La Houille Blanche $\mathrm{N}^{\circ}$ 7. pp. 68-74, 1995.

10. F. Naaim-Bouvet, M. Naaim, H. Martinez, "Profils de concentration de la neige souffléethéorie, résolution numérique et validation expérimentale In-situ", In la Houile Blanche $\mathrm{N}^{\circ}$ 5. pp. 53-56, 1996.

11. J. Nougara, "Mécanique des fluides expérimentale. Ecole Nationale Supérieure d'Electronique d'Informatique et d'Hydraulique Université de Toulouse", 1968. 
12. R. Rémini, "Méga-obstacles et dépressions, leurs influences sur la dynamique éolienne, les ergs et l'ensablement des espaces oasiens", Thèse de Doctorat, Laboratoire de Géographie Zonale pour le Développement, Université de Reims Champagne-Ardenne, France. 208p, 2002.

13. A. Rémini, "Etude expérimentale de l'évolution de l'ensablement derrière les brise-vents", Journal. Alg. Rég. Arides. № 5. pp. 23-28, 2006.

14. M. Rouvillois - Brigol, "Le pays d’Ouargla (Sahara Algérien)", Paris : Dep. Géog Université de Paris-Sorbonne. 390p, 1975.

15. A.K. Sebaa, S. Berroussi, M. Bouhanna, M.T. Benazzouz, "Utilisation des méthodes traditionnelles de lutte contre l'ensablement dans le Bas-Sahara Algérien : le tas de remblai", Journal Algérien des Régions Arides. № 08. pp. 107-117, 2009.

16. D. Soltner, "Les bases de la production végétale", Tome 1. Le sol et son amélioration. $24^{e}$ éd. Paris : CRSTRA. 472p, 2005.

17. A.R. Voisin, "Le Souf, monographie", EL-Oued : EL Walid. 319 p, 2004. 